\title{
Outcome and patterns of failure after postoperative intensity modulated radiotherapy for locally advanced or high-risk oral cavity squamous cell carcinoma
}

\author{
Andreas Geretschläger ${ }^{1}$, Beat Bojaxhiu', Susanne Crowe ${ }^{2}$, Andreas Arnold ${ }^{3}$, Peter Manser ${ }^{1}$, Wock Hallermann ${ }^{4}$, \\ Daniel M Aebersold ${ }^{1}$ and Pirus Ghadjar ${ }^{1 *}$
}

\begin{abstract}
Background: To determine the outcome and patterns of failure in oral cavity cancer (OCC) patients after postoperative intensity modulated radiotherapy (IMRT) with concomitant systemic therapy.

Methods: All patients with locally advanced (AJCC stage III/IV) or high-risk OCC (AJCC stage II) who underwent postoperative IMRT at our institution between December 2006 and July 2010 were retrospectively analyzed. The primary endpoint was locoregional recurrence-free survival (LRRFS). Secondary endpoints included distant metastasis-free survival (DMFS), overall survival (OS), acute and late toxicities.
\end{abstract}

Results: Overall 53 patients were analyzed. Twenty-three patients (43\%) underwent concomitant chemotherapy with cisplatin, two patients with carboplatin (4\%) and four patients were treated with the monoclonal antibody cetuximab (8\%).

At a median follow-up of 2.3 (range, 1.1-4.6) years the 3-year LRRFS, DMFS and OS estimates were 79\%, 90\%, and 73\% respectively. Twelve patients experienced a locoregional recurrence. Eight patients, 5 of which had both a flap reconstruction and extracapsular extension (ECE), showed an unusual multifocal pattern of recurrence. Ten locoregional recurrences occurred marginally or outside of the high-risk target volumes. Acute toxicity grades of 2 (27\%) and $3(66 \%)$ and late toxicity grades of $2(34 \%)$ and $3(11 \%)$ were observed.

Conclusion: LRRFS after postoperative IMRT is satisfying and toxicity is acceptable. The majority of locoregional recurrences occurred marginally or outside of the high-risk target volumes. Improvement of high-risk target volume definition especially in patients with flap reconstruction and ECE might transfer into better locoregional control.

Keywords: Head and neck cancer, IMRT, Oral cavity, Outcome, Postoperative

\section{Background}

Treatment of locally advanced or high-risk oral cavity cancer (OCC) involves extensive surgical procedures, often combined with flap reconstruction, followed by postoperative radiotherapy (RT) with systemic therapy if certain risk factors are present. Postoperative RT as compared to preoperative RT has been shown to increase locoregional control of patients with locally advanced

\footnotetext{
* Correspondence: pirus.ghadjar@insel.ch

1 Department of Radiation Oncology and Division of Medical Radiation Physics, Bern University Hospital, Freiburgstrasse, 3010 Bern, Switzerland Full list of author information is available at the end of the article
}

head and neck cancer [1]. In addition postoperative RT increased overall survival (OS) in nodal positive patients as compared to surgery alone [2]. Furthermore postoperative cisplatin based chemoradiation is known to increase time to locoregional recurrence as well as OS in patients with positive resection margins and lymph node metastasis with extracapsular extension (ECE) [3]. Recently, the development of intensity modulated RT (IMRT) significantly reduced xerostomia when compared to 3-dimensional conformal RT in a randomized controlled trial $[4,5]$ and swallowing sparing IMRT has been described to potentially reduce RT related dysphagia [6].

\section{() Biomed Central}

(c) 2012 Geretschläger et al.; licensee BioMed Central Ltd. This is an Open Access article distributed under the terms of the Creative Commons Attribution License (http://creativecommons.org/licenses/by/2.0), which permits unrestricted use, distribution, and reproduction in any medium, provided the original work is properly cited. 
In 2006/2007 we reevaluated our institutional policy for IMRT treatment of OCC patients. Having started IMRT treatments in 2002, we could draw upon own experience and patient results as well as a small number of publications [7-13]. We then adapted our institutional guidelines for treatment and follow-up with a special focus on target volume definition and dose prescription. We have now retrospectively analyzed the outcome and patterns of failure of patients at our center having been treated accordingly.

\section{Methods}

\section{Patient selection}

We retrospectively identified all patients with newly diagnosed OCC with either locally advanced disease (American Joint Committee on Cancer (AJCC) stage III or IV) or early stage high-risk disease (positive or close margins $(<3 \mathrm{~mm})$; perineural invasion; lymphovascular space invasion and synchronous primary tumors) who underwent postoperative IMRT between December 2006 and July 2010 at our Department of Radiation Oncology, Inselspital, Bern University Hospital. Patients with a history of another malignancy within 5 years, histology other than squamous cell carcinoma, distant metastatic disease or prior neoadjuvant therapy were excluded. Patients were staged according to the AJCC 2002 guidelines [14]. This study was approved by the local ethics committee.

\section{Treatment}

Prior to start of any treatment, stage of disease, sequence of treatment and modalities were defined in the weekly interdisciplinary institutional head-and-neck tumorboard for all patients.

\section{Surgery}

All patients underwent resection of the primary tumor and an uni- or bilateral modified radical neck dissection in the Department of Otorhinolaryngology, Head and Neck Surgery and / or Department of Craniomaxillofacial Surgery, Inselspital Bern, University Hospital. In cN+ patients aim of surgery was complete resection of the primary tumor and of all cervical metastastic lymph nodes. The decision to do selective neck dissections in cases with $\mathrm{cNO}$ or in the contralateral node negative neck was at the discretion of the head and neck surgeon.

\section{Radiotherapy}

Prior to IMRT planning all patients were referred for dental evaluation and treatment if necessary. For treatment planning a dedicated high-resolution CT scan with $3 \mathrm{~mm}$ slices and intravenous contrast was used. Patients were immobilized in the supine position using a thermoplastic mask covering head and shoulders. A bite block / tongue depressor was used to separate upper from lower jaw, all patients were additionally told to extend their (remaining) tongue to reach the backside of their lower jaw incisors and keep the tongue in this position during treatment if possible. All visible surgical scars were marked with flexible wires.

It was our policy to contour the resected tumor and all metastatic lymph nodes in their former location and full dimension in the planning $\mathrm{CT}$ if possible, using all available information (clinical descriptions, all preoperative imaging modalities, surgical reports). Additional image fusion of preoperative MRI or PET-CT was performed if deemed useful. Three different risk levels of clinical target volume (CTV) were defined. CTV72 was defined as gross tumor either due to early postoperative tumor progression with an additional isotropic margin of $1.5 \mathrm{~cm}$ and treated to 72 Gy. CTV60-66 was defined as the former tumor bed (FTB), areas with microscopically incomplete resection (R1) and all neck levels having harboured lymph node metastasis with ECE with an additional isotropic margin of $1.5 \mathrm{~cm}$. In case of reported intraoperative spillage (tumor and / or metastatic lymph node rupture) the whole corresponding surgically manipulated area was defined as CTV60-66, e.g. the complete area of neck dissection [15]. All of CTV6066 was treated to 66 Gy except in a few cases of R0 resection of the primary tumor with generous margins (>5 mm), where the FTB was treated to 60 instead of 66 Gy. CTV54 included the CTV72 or CTV60-66 plus dissected lymph node levels with 1 (pN1) or more metastatic lymph nodes (pN2b, pN2c) without ECE and the elective contralateral not dissected neck levels in case of unilateral neck dissection and was treated to 54 Gy. The definition of elective nodal target volumes followed the recommendations proposed by Eisbruch et al. [16]. All prescribed CTV-margins were anatomically adapted to account for natural barriers such as thyroid and cricoid cartilage, hyoid, mandibular or vertebral bone and for skin and air. The resulting CTVs were finally expanded to planning target volumes (PTVs) by adding a symmetric $3 \mathrm{~mm}$ margin for setup error compensation. In a final adjustment all PTVs were set back from the skin surface 3-5 $\mathrm{mm}$ to allow for dose build-up except where the skin was deemed to be at risk of harbouring microscopic tumor e.g. the neck dissection scar in case of tumor spillage. Instead of using a skin flap in these cases we tried to optimize dose build-up by putting more weight on tangential beam directions accepting minor under-dosages. All planning PTVs were treated sequentially in a "shrinking-volume" technique with a fractionation of 5 times 2 Gy per week, resulting in two or three treatment plans per patient. Dose prescription was done to the median dose D50\% of the PTV in accordance with the ICRU report 83. All treatment plans were contoured and 
Table 1 Patient and treatment characteristics $(n=53)$

\section{Characteristics}

Age (years)\#

$\leq 60$

$>60$

Gender

Female

Male

Karnowsky PS

$$
>70
$$$$
\leq 70
$$

Site

Tongue

Floor of mouth

Alveolus and Gingiva

Others*

n (\%)

25 (47)

$28(53)$

$17(32)$

$36(68)$

$42(79)$

$11(21)$

$22(41)$

17 (32)

$11(21)$

$3(6)$

Tumor classification

pT1

pT2

pT3

pT4

Nodal classification

$\mathrm{CNO}{ }^{* *}$

pNO

pN1

pN2

pN3

Grading

Moderate (G2)

Poor (G3)

Resection margins

RO

Close $(<3 \mathrm{~mm})$

R1

Surgery to primary tumor

Wide local excision

Partial glossectomy

Hemiglossectomy

Mandibular resection

Partial maxillectomy

Composite oral cavity resection

Neck dissection\#\#

None

Ipsilateral

Bilateral
8 (15)

25 (47)

$5(10)$

15 (28)

$2(4)$

18 (34)

10 (19)

$22(41)$

1 (2)

$37(70)$

16 (30)

25 (47)

$13(25)$

18 (34)

4 (7)

4 (7)

$3(6)$

15 (29)

$23(43)$
Table 1 Patient and treatment characteristics $(n=53)$ (Continued)

Gastrostomy tube

None

Used

$25(47)$

Abbreviations: PS performance status; \# median 60 years (range, $40-88$ years); * buccal mucosa $n=2$ and hard palate $n=1$; **Two patients (4\%) did not undergo a neck dissection; \#\# Of the 51 patients who underwent a neck dissection a median of 44 nodes (range, 14-101 nodes) were removed.
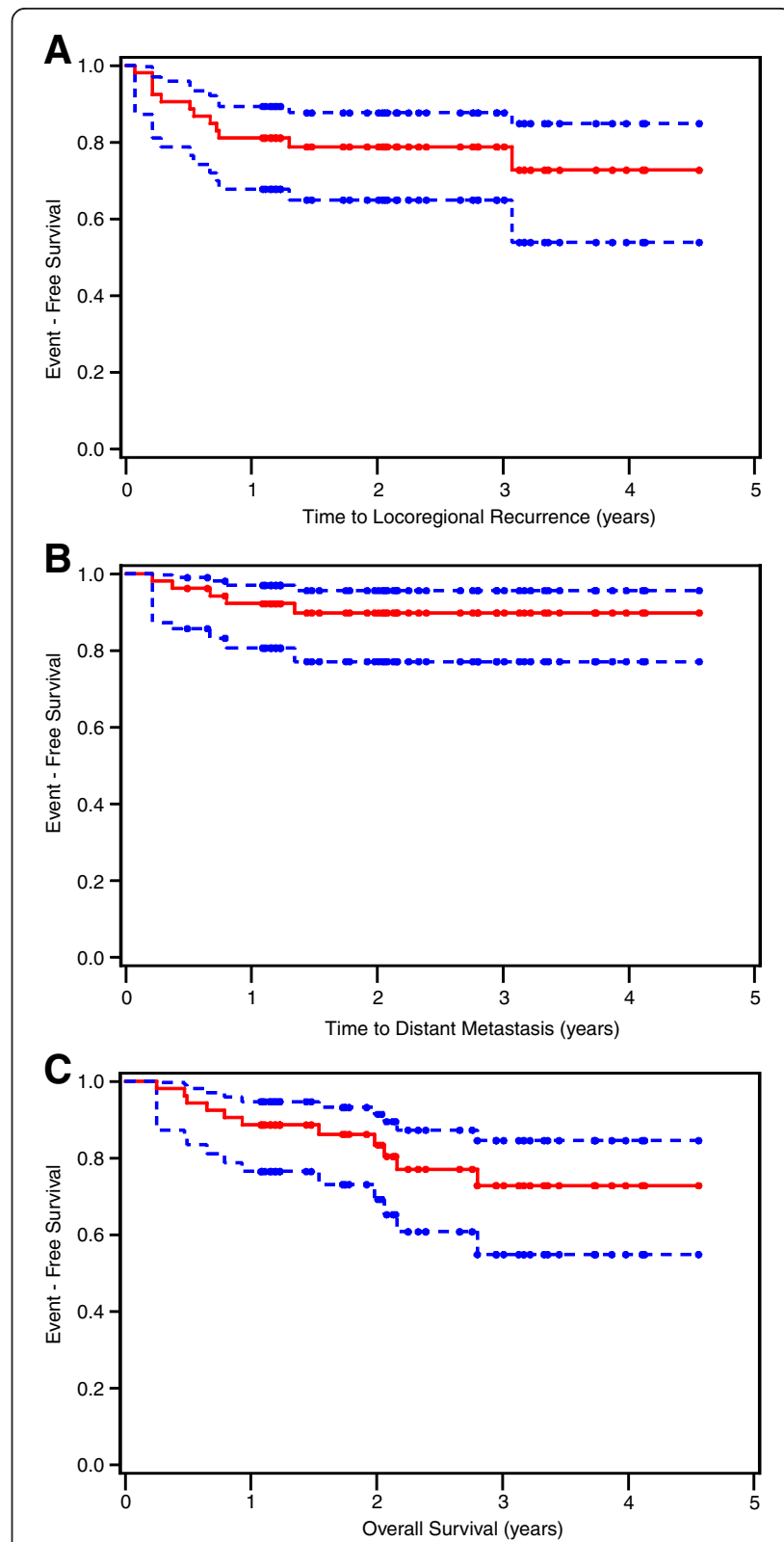

Figure 1 Locoregional recurrence-free survival (LRRFS) (A), distant metastasis-free survival (DMFS) (B) and overall survival (OS) (C). 
calculated by Eclipse treatment planning system (Varian Medical Systems, Palo Alto, CA).

\section{Concomitant systemic therapy}

The standard concomitant therapy consisted of cisplatin $100 \mathrm{mg} / \mathrm{m} 2$ day1 in three week intervals for all patients. Patients not deemed fit for cisplatin chemotherapy because of pre-existing co-morbidities or poor overall performance status were occasionally evaluated for treatment with either carboplatin or the monoclonal antibody cetuximab in an individual therapeutic approach by the responsible medical oncologist knowing that there is until present no sufficient data to prove the benefit of this treatment.

\section{Assessments and evaluations}

After RT all patients underwent follow-up visits on a regular basis. These visits were scheduled every 3 months for the first 2 years, twice a year until the 5th year and yearly thereafter. For this study the follow-up information closeout date was September 2011. Eight to twelve weeks after the end of treatment a post-therapy baseline CT or MRI was performed.

Time-to-event endpoints were calculated from end of RT until the date of event. Patients not experiencing an event were censored at the date of the last follow-up visit.
Toxicities were graded according to the National Cancer Institute (NCI) Common Terminology Criteria for adverse events (CTCAE) version 3.0. The symptoms pain, dermatitis, mucositis, dysphagia, xerostomia and osteonecrosis were assessed. Acute toxicity was defined as complications during RT and until 3 months after end of RT; late toxicity as complications occurring thereafter.

\section{Analysis of recurrences}

The recurrent or persistent tumor volume as defined by all available diagnostic images, was used to categorize the recurrences as "in-volume", if $>95 \%$ of the recurrent locoregional tumor volume was within the corresponding CTV54, CTV60-66 or CTV72; "marginal", if $20-95 \%$ was within the CTV54, CTV60-66 or CTV72; or "out-volume", if $<20 \%$ of the recurrent tumor volume was within the respective CTV, as previously described $[17,18]$. The relation of all recurrences to both CTVs was assessed sequentially.

\section{Statistical considerations}

The primary endpoint was locoregional recurrence-free survival (LRRFS). Secondary endpoints included distant metastasis-free survival (DMFS), OS, acute and late toxicity. Late toxicity at last follow-up visit was also assessed to determine whether the late toxicity persisted or was transient.

Time-to-event endpoints were estimated using the Kaplan Meier method. Univariate and multivariate analyses were

Table 2 Treatment outcome analysis

\begin{tabular}{|c|c|c|c|c|}
\hline \multirow[t]{2}{*}{ Factor } & \multirow[t]{2}{*}{ Associated level } & \multicolumn{3}{|c|}{ Cox regression analysis hazard ratio $(95 \% \mathrm{Cl})$ (p-value) } \\
\hline & & LRRFS & DMFS & OS \\
\hline \multicolumn{5}{|l|}{ Univariate analysis } \\
\hline Age (years) & $>60$ & $1.31(0.42,4.13)(0.64)$ & $1.44(0.24,8.62)(0.69)$ & $2.46(0.65,9.28)(0.18)$ \\
\hline Sex & Male & $0.92(0.27,3.07)(0.89)$ & $0.75(0.12,4.48)(0.75)$ & $1.81(0.39,8.44)(0.45)$ \\
\hline KPS & $\leq 70$ & $1.20(0.32,4.44)(0.79)$ & $0.94(0.11,8.46)(0.96)$ & $0.74(0.16,3.42)(0.70)$ \\
\hline T-classification & $\mathrm{pT}_{3-4}$ & $1.73(0.56,5.37)(0.34)$ & $2.44(0.41,14.58)(0.33)$ & $1.43(0.44,4.70)(0.55)$ \\
\hline N-classification & $\mathrm{pN}_{2-3}$ & $4.71(1.27,17.45)(0.02)$ & $114.6(0.06,>1000)(0.22)$ & $4.65(1.23,17.63)(0.02)$ \\
\hline AJCC stage & IV & $4.43(0.97,20.27)(0.05)$ & $56.7(0.04,>1000)(0.27)$ & $4.13(0.90,19.10)(0.07)$ \\
\hline Grading & G3 & $1.82(0.58,5.73)(0.31)$ & $3.4(0.57,20.4)(0.18)$ & $0.89(0.24,3.40)(0.87)$ \\
\hline Resection margins & R1 & $0.65(0.14,2.98)(0.58)$ & $0.78(0.09,6.96)(0.82)$ & $1.73(0.50,5.93)(0.38)$ \\
\hline ECE positive LN & yes & $2.29(0.74,7.14)(0.15)$ & $3.54(0.58,21.4)(0.17)$ & $2.19(0.66,7.27)(0.20)$ \\
\hline Chemotherapy* & yes & $0.56(0.18,1.75)(0.32)$ & $1.15(0.19,6.89)(0.88)$ & $0.44(0.13,1.50)(0.20)$ \\
\hline Flap reconstruction & yes & $1.92(0.58,6.42)(0.29)$ & $59.4(0.04,>1000)(0.27)$ & $2.48(0.66,9.35)(0.16)$ \\
\hline Bilateral ND & yes & $0.38(0.10,1.40)(0.15)$ & $0.74(0.12,4.46)(0.75)$ & $0.59(0.17,2.01)(0.40)$ \\
\hline Gastrostomy tube & yes & $1.68(0.53,5.30)(0.38)$ & $1.70(0.28,10.17)(0.56)$ & $1.03(0.31,3.38)(0.96)$ \\
\hline Time OP to RT & $>6$ weeks & $0.59(0.19,1.89)(0.38)$ & $0.73(0.12,4.37)(0.73)$ & $0.68(0.19,2.35)(0.54)$ \\
\hline \multicolumn{5}{|l|}{ Multivariate analysis } \\
\hline N-classification & $\mathrm{pN}_{2-3}$ & $4.71(1.27,17.45)(0.02)$ & n.a. & $4.65(1.23,17.63)(0.02)$ \\
\hline AJCC stage & IV & $1.68(0.15,18.51)(0.67)$ & n.a. & $1.53(0.14,16.94)(0.73)$ \\
\hline
\end{tabular}

Abbreviations: LRRFS Locoregional recurrence-free survival, DMFS Distant metastasis-free survival, OS Overall survival, OP surgery, KPS Karnowsky performance score, ECE extracapsular extention, $L N$ lymph node, n.a. not applicable, ND neck dissection, *including treatment with cetuximab. 
Table 3 Localization and pattern of tumor recurrences in relation to the clinical target volumes

\begin{tabular}{|c|c|c|c|c|c|c|c|c|c|c|c|}
\hline $\begin{array}{l}\text { Site of } \\
\text { Primary }\end{array}$ & $\mathbf{T}$ & $\mathrm{N}$ & $\mathbf{R}$ & ECE & Flap & $\begin{array}{l}\text { Systemic } \\
\text { therapy }\end{array}$ & $\begin{array}{l}\text { Time to } \\
\text { recurrence } \\
\text { (yrs) }\end{array}$ & $\begin{array}{l}\text { Compartment } \\
\text { of recurrence }\end{array}$ & $\begin{array}{l}\text { Localization and pattern of } \\
\text { recurrence }\end{array}$ & $\begin{array}{l}\text { Relation of } \\
\text { recurrence } \\
\text { to CTV } 54\end{array}$ & $\begin{array}{l}\text { Relation of } \\
\text { recurrence } \\
\text { to CTV60-66 }\end{array}$ \\
\hline \multirow[t]{2}{*}{$\begin{array}{l}\text { Floor of } \\
\text { mouth }\end{array}$} & \multirow[t]{2}{*}{4} & \multirow[t]{2}{*}{$2 b$} & \multirow[t]{2}{*}{$c$} & \multirow[t]{2}{*}{ Yes } & \multirow[t]{2}{*}{ Yes } & \multirow[t]{2}{*}{ Yes } & 0.2 & Local & $\begin{array}{l}\text { Outside FTB, not involving flap, } \\
\text { multifocal }\end{array}$ & \multirow{2}{*}{$\begin{array}{c}\text { Marginal } \\
\text { n.a }\end{array}$} & Marginal \\
\hline & & & & & & & 0.8 & Distant & Lung & & n.a \\
\hline $\begin{array}{l}\text { Floor of } \\
\text { mouth }\end{array}$ & 1 & $2 b$ & c & No & No & Yes & 3.1 & Local & $\begin{array}{c}\text { Outside FTB, ipsilateral dorsal edge } \\
\text { of tongue, unifocal }\end{array}$ & Marginal & Marginal \\
\hline \multirow{2}{*}{$\begin{array}{l}\text { Floor of } \\
\text { mouth }\end{array}$} & \multirow[t]{2}{*}{4} & \multirow[t]{2}{*}{$2 b$} & \multirow[t]{2}{*}{$c$} & \multirow[t]{2}{*}{ Yes } & \multirow[t]{2}{*}{ Yes } & \multirow[t]{2}{*}{ Yes } & 0.7 & Local & Within FTB and flap, multifocal & \multirow{2}{*}{$\begin{array}{l}\text { In } \\
\text { n.a }\end{array}$} & \multirow{2}{*}{$\begin{array}{l}\text { Marginal } \\
\text { n.a }\end{array}$} \\
\hline & & & & & & & 0.7 & Distant & Lung & & \\
\hline \multirow{3}{*}{$\begin{array}{l}\text { Lower } \\
\text { alveolar ridge }\end{array}$} & \multirow{3}{*}{4} & \multirow[t]{3}{*}{$2 b$} & \multirow[t]{3}{*}{1} & \multirow[t]{3}{*}{ Yes } & \multirow[t]{3}{*}{ Yes } & \multirow[t]{3}{*}{ No } & 0.3 & Local & Within FTB and flap, multifocal & \multirow{2}{*}{$\ln$} & \multirow{2}{*}{$\ln$} \\
\hline & & & & & & & 0.3 & Regional & Ipsilateral neck, multifocal & & \\
\hline & & & & & & & 0.4 & Distant & Lung, Pleura, Skin, Liver & n.a & n.a \\
\hline \multirow[t]{2}{*}{ Tongue } & \multirow[t]{2}{*}{2} & \multirow[t]{2}{*}{$2 b$} & \multirow[t]{2}{*}{ c } & \multirow[t]{2}{*}{ No } & No & No & 0.5 & Local & Within FTB, unifocal & & \\
\hline & & & & & & & 0.5 & Regional & $\begin{array}{c}\text { Bilateral neck (ipsilateral bulky), } \\
\text { multifocal }\end{array}$ & $\ln$ & Marginal \\
\hline Tongue & 2 & $2 b$ & 0 & No & Yes & No & 0.2 & Local & Within FTB and flap, unifocal & $\ln$ & Marginal \\
\hline & & & & & & & 0.2 & Regional & Bilateral neck, multifocal & (11 & \\
\hline & & & & & & & 0.2 & Distant & Pleura & n.a & n.a \\
\hline $\begin{array}{l}\text { Buccal } \\
\text { mucosa }\end{array}$ & 2 & $2 b$ & 1 & Yes & Yes & Yes & 0.1 & Local & $\begin{array}{l}\text { Within bed of surgical resection and } \\
\text { flap, multifocal }\end{array}$ & Marginal & Marginal \\
\hline & & & & & & & 0.1 & Regional & Contralateral neck, unifocal & & \\
\hline Tongue & 3 & $2 b$ & 0 & Yes & Yes & No & 0.7 & Local & Within FTB and flap, multifocal & $\ln$ & Marginal \\
\hline & & & & & & & 0.7 & Regional & Contralateral neck, unifocal & & \\
\hline Tongue & 2 & 0 & 0 & No & No & No & 0.7 & Local & Within FTB, unifocal & & \\
\hline & & & & & & & 0.7 & Regional & Contralateral neck, multifocal & Marginal & Mlarginal \\
\hline Tongue & 3 & $2 c$ & c & Yes & Yes & Yes & 0.7 & Regional & Contralateral neck, unifocal & $\ln$ & $\ln ^{*}$ \\
\hline Tongue & 1 & 0 & c & No & No & No & 1.3 & Regional & Contralateral neck, unifocal & Out & Out \\
\hline $\begin{array}{l}\text { Lower } \\
\text { alveolar } \\
\text { ridge, edge } \\
\text { of tongue }\end{array}$ & 4 & 0 & 0 & No & Yes & No & 0.5 & Regional & $\begin{array}{l}\text { Outside FTB, not involving flap, } \\
\text { extending to ipsilateral base of skull } \\
\text { and Fossa infratemporalis, unifocal }\end{array}$ & Out & Out \\
\hline
\end{tabular}

Abbreviations: $T$ tumor classification, $N$ nodal classification, $R$ resection margin, $c$ close $(<3 \mathrm{~mm}), C T V$ clinical target volume, n.a. not applicable; FTB former tumor bed, CTV clinical target volume, *this patient was one of the two patients who received a total dose of $72 \mathrm{~Gy}$, the regional recurrence was inside the CTV72Gy.

performed using Cox proportional hazards models and the backward selection method (criterion for removal: $p \geq 0.05$ ). To be assessed in the multivariate analysis, a variable had to be significant $(p \leq 0.1)$ in the univariate analysis. Categorical variables were summarized using absolute and relative frequencies; continuous variables by descriptive statistics. P-values were two-sided, not adjusted for multiple testing, and considered significant if $<0.05$. The data were analyzed in SPSS (SPSS Inc., Chicago, IL, version 19.0) and SAS (Statistical Analysis Systems Institute Inc, version 9.2).

\section{Results}

\section{Patient and treatment characteristics}

In total 53 patients were retrospectively analyzed. Seven and thirty patients had AJCC stage III (13\%) or IV
(57\%), in the remaining 16 patients with AJCC stage I/II (30\%), the following risk factors were present: positive margins $(n=2)$, close margins $(n=9)$, perineural invasion $(n=3)$, lymphovascular space invasion $(n=2)$ and 1 patient had 2 synchronous primary tumors (buccal mucosa and tongue). Pre-treatment staging of the head and neck was performed by either CT $(n=33)$, MRI $(n=12)$ or both $(n=8)$. Prior to treatment, a PET-CT scan was used on 9 patients (17\%). A total of 17 patients were ECE positive. Twenty-nine patients (55\%) underwent soft tissue reconstruction using either a local musculocutaneous pedicled flap $(n=17)$, regional musculocutaneous pedicled flap $(n=6)$ or free flap $(n=6)$. ECE was detected in 11 flap reconstruction cases. Further patient and treatment characteristics are summarized in Table 1. Median time between surgery and RT was 6.7 (range, 3-17) weeks. 
Table 4 Pre-treatment morbidity and acute and late toxicity

\begin{tabular}{|c|c|c|c|c|c|}
\hline & & Pre-Tx & Acutet & Late‡ & Last late§ \\
\hline Toxicity & Grade & n (\%) & n (\%) & n (\%) & n (\%) \\
\hline \multirow[t]{4}{*}{ Pain } & 0 & $31(59)$ & $1(2)$ & $42(80)$ & $47(89)$ \\
\hline & 1 & $16(30)$ & $12(23)$ & $4(7)$ & 0 \\
\hline & 2 & $6(11)$ & $32(60)$ & $5(9)$ & $5(9)$ \\
\hline & 3 & - & $8(15)$ & $2(4)$ & $1(2)$ \\
\hline \multirow[t]{4}{*}{ Dermatitis } & 0 & $53(100)$ & - & $51(96)$ & $53(100)$ \\
\hline & 1 & - & $14(26)$ & $1(2)$ & - \\
\hline & 2 & - & $30(57)$ & $1(2)$ & - \\
\hline & 3 & - & $9(17)$ & - & - \\
\hline \multirow[t]{4}{*}{ Mucositis } & 0 & $53(100)$ & - & $50(94)$ & $53(100)$ \\
\hline & 1 & - & $7(13)$ & $1(2)$ & - \\
\hline & 2 & - & $27(51)$ & $1(2)$ & - \\
\hline & 3 & - & $19(36)$ & $1(2)$ & - \\
\hline \multirow[t]{4}{*}{ Dysphagia } & 0 & $25(47)$ & $5(9)$ & $28(53)$ & $35(66)$ \\
\hline & 1 & $4(7)$ & $5(9)$ & $4(7)$ & $7(14)$ \\
\hline & 2 & $17(32)$ & $25(48)$ & $16(31)$ & $6(11)$ \\
\hline & 3 & $7(14)$ & $18(34)$ & $5(9)$ & $5(9)$ \\
\hline \multirow[t]{4}{*}{ Xerostomia } & 0 & $53(100)$ & $37(70)$ & $34(64)$ & $40(75)$ \\
\hline & 1 & - & $13(24)$ & $15(29)$ & $10(19)$ \\
\hline & 2 & - & $3(6)$ & $4(7)$ & $3(6)$ \\
\hline & 3 & - & - & - & - \\
\hline \multirow[t]{3}{*}{ Osteonecrosis } & 0 & $53(100)$ & $52(98)$ & $51(96)$ & $53(100)$ \\
\hline & 1 & - & - & - & - \\
\hline & 2 & - & $1(2)$ & $2(4)$ & - \\
\hline \multirow[t]{4}{*}{ Highest* } & 0 & $19(36)$ & - & $18(34)$ & $30(57)$ \\
\hline & 1 & $7(13)$ & $4(7)$ & $11(21)$ & $11(21)$ \\
\hline & 2 & $20(38)$ & $14(27)$ & $18(34)$ & 7 (13) \\
\hline & 3 & 7 (13) & $35(66)$ & $6(11)$ & $5(9)$ \\
\hline
\end{tabular}

Abbreviations: Pre-Tx pre-treatment morbidity; * The highest morbidity/toxicity in a patient was counted as a single event; $\uparrow$ During therapy and until 3 months after completion; ₹ maximal late toxicity $>3$ months after completion of therapy; § Incidence of late toxicity at last follow-up visit. Percentages were rounded to reach $100 \%$ for every symptom.

Median total RT dose was 66 (range, 60-72) Gy. Two patients received 72 Gy as there was evidence of macroscopic neck metastasis during treatment planning.

Twenty-five patients (47\%) underwent concomitant chemotherapy (cisplatin $n=23$, carboplatin $n=2$ ). The median number of chemotherapy cycles was 3 (range, $2-3)$. Four patients $(8 \%)$ underwent treatment with the monoclonal antibody cetuximab. The median follow-up was 2.3 (range, 1.1-4.6) years for the surviving patients.

\section{Locoregional recurrence}

At the time of analysis, 9 local recurrences and 9 regional recurrences were observed in 12 patients. Of those patients, 3 had only local recurrence, three had only regional recurrence and 6 had both. The median time to locoregional recurrence was not reached. The 2and 3-year LRRFS estimates were both 79\% (Figure 1A). In a multivariate Cox proportional hazards model, $\mathrm{N}$ classification $>$ N1 remained a significant prognostic factor for LRRFS (hazard ratio (HR): 4.7; 95\% Confidence interval (CI): 1.3-17.4; $p=0.02$ )) (Table 2).

The patterns of failure analysis revealed that 8 out of 12 locoregional recurrences showed an unusual multifocal pattern of recurrence, five of these patients had a flap reconstruction and ECE. Six of the total 12 locoregional recurrences occurred within the CTV54; 10 of the 12 marginally or outside of the CTV60-66 or CTV72 (Table 3).

\section{Distant metastasis}

At the time of analysis 5 patients had developed distant metastasis, located in the lung, pleura, skin $(n=1)$, bone and soft tissue $(n=1)$, pleura $(n=1)$ or lung only $(n=2)$. All patients who developed metastasis had also either local or regional recurrence. The 2- and 3-year DMFS estimates were both 90\% (Figure 1B). No clinical or pathological variable was found to be associated with distant metastasis (Table 2).

\section{Overall survival}

Eleven patients (21\%) died during follow-up; 9 due to cancer progression (cancer specific deaths), one patient due to cachexia and the other due to cardiac failure. The 2- and 3year OS estimates were $83 \%$ and $73 \%$ (Figure 1C), and the respective cancer-specific survival rates were $85 \%$ and $82 \%$. In a multivariate Cox proportional hazards model using backward selection, N-classification $>\mathrm{N} 1$ was the only significant prognostic factor for OS (HR: 4.6, 95\% CI: 1.2-17.6; $p=0.02$ ) (Table 2).

\section{Pre-RT morbidity and acute and late toxicity}

After surgery and prior to RT, pre-RT morbidity was determined (Table 4). Six patients (11\%) were identified with pre-RT grade 2 pain, 17 (32\%) had pre-RT grade 2 dysphagia and 7 (14\%) had pre-RT grade 3 dysphagia.

The highest grade of acute toxicity was: grade 2 in 14 patients (27\%); grade 3 in 35 patients (66\%). No toxicity related interruptions of RT occurred. The highest grade of late toxicity was: grade 2 in 18 patients (34\%); grade 3 in 6 patients (11\%). At the last follow-up visit the highest grade of late toxicity was: grade 2 in 7 patients (13\%); grade 3 in 5 patients (9\%).

\section{Discussion}

Since 2007 the outcome and patterns of failure of postoperative IMRT for OCC have been described by others [7-13]. 
Our patient selection equals those of the mentioned publications in regard to median age, TNM and AJCC stage, median follow-up and time interval between surgery and RT. Our CTV definitions and dose prescriptions are almost identical to those reported by Sher et al. [13], the relevant difference being that we prescribed 54 Gy to dissected and involved lymph node levels in the absence of ECE instead of 60 Gy. The CTV definitions and dose prescriptions of the remaining publications vary considerably in detail, especially when describing high-risk CTV. The FTB is uniformly assigned doses around 70 Gy in case of gross residual disease and 66 Gy in R1 except by Chen et al. [10] who applied a median dose of 61.1 Gy. The prescription range for dissected lymph node levels containing metastatic nodes is 60-66 Gy in the presence of ECE and 54-60 Gy without ECE, elective (low neck and contralateral) lymph node levels are prescribed 46.8 to $56 \mathrm{~Gy}$.

The 2- and 3-year LRRFS, DMFS and OS estimates observed in our study compare well with previously published reports (Table 5). N-classification was the only significant prognostic factor for both LRRFS and OS in multivariate analysis, consistent with the findings of Chen et al. [10]. Others reported ECE or positive margins and total treatment time as significant $[8,11]$.

Our patterns of failure analysis revealed an unusual multifocal recurrence pattern in 8 out of 12 patients involving areas of tumor resection, neck dissection and flap reconstruction making a precise allocation into categories of "local" or "regional" recurrence quite impossible. In relation to CTV54 and CTV60-66 or CTV72 coverage the recurrences showed an unexpected variety (Table 3 ) with "marginal" and "out" volume recurrences in relation to both CTVs. Four patients had multifocal recurrences completely covered by CTV54; therefore they could have been reported as "in" volume recurrences, but because less than
95\% of all recurrent tumor masses were covered by CTV66 we additionally report them as "marginal" to CTV66. One of these patients for example recurred in the FTB and in the ipsilateral dissected and contralateral not dissected neck with 6 volumes of tumor all within CTV54, whereas 2 recurrences in the contralateral Level I were not covered by CTV60-66. Thus, in 10 out of 12 patients the locoregional recurrence occurred marginally or outside of the high-risk target volumes. A similar pattern of failure is reported by Yao et al. [8] with 4 out of 9 locoregional failures being multifocal and 3 of these 4 failing in both CTV60 and CTV64-66, though neither aspect is discussed in the paper. Daly et al. [11] give a detailed description of 13 locoregional treatment failures after postoperative RT, with only 3 failures "entirely within high-risk PTV60 or PTV66" and 2 multifocal failures not assessed in respect to PTV coverage at all, meaning the remaining 8 failures were at least "marginal" or "out" of the high-risk volume. The remaining publications however $[7,9,10,13]$ do not quantify dose coverage of their failures and do not describe multifocal recurrences. We therefore propose to describe recurrences as unifocal or multifocal as this is an important predictor for surgical salvage [19].

Eight out of our 12 recurrences had extensive surgery requiring flap reconstruction, and 5 of these failed multifocally involving the flap reconstruction. All of these 5 patients had ECE, and there might have been tumor cell spillage during surgery [15]. Finding no proposals for target volume delineation regarding flap reconstructions in an extensive literature search we have now started to fully include flap reconstructions in the CTV54 in case of synchronous ECE.

Another one of our patients with extensive perineural invasion failed "out" of treatment volume having recurred in the ipsilateral infratemporal fossa with tumor cells

Table 5 Treatment details and results of retrospective reports with postoperative IMRT in oral cavity cancer

\begin{tabular}{|c|c|c|c|c|c|c|c|c|c|}
\hline $\begin{array}{l}\text { Report } \\
\text { (reference) }\end{array}$ & $n$ & $\begin{array}{l}\text { Median age } \\
\text { (years) }\end{array}$ & Stage (\%) & $\begin{array}{l}\text { Median Time from } \\
\text { surgery to RT (weeks) }\end{array}$ & $\begin{array}{l}\text { Systemic } \\
\text { therapy (\%) }\end{array}$ & $\begin{array}{l}\text { Median } \\
\text { follow-up } \\
\text { (mts) }\end{array}$ & LRFS (\%) & LRRFS (\%) & OS (\%) \\
\hline \multirow[t]{2}{*}{ Studer (7) } & 28 & $61^{*}$ & III (14) & $\mathrm{nr}$ & 86 & 19 & $92 \#$ & $\mathrm{nr}$ & 83\# \\
\hline & & & IV (54) & & & & & & \\
\hline \multirow[t]{2}{*}{ Chen (10) } & 22 & 50 & III (27) & $\mathrm{nr}$ & 9 & 44 & $\mathrm{nr}$ & $64^{* *}$ & 679 \\
\hline & & & IV (73) & & & & & & \\
\hline \multirow[t]{2}{*}{ Gomez (9) } & 35 & $\mathrm{nr}$ & III (26) & 7 & 29 & 28 & $89^{* *}$ & 77 & 74 \\
\hline & & & IV (54) & & & & & & \\
\hline \multirow[t]{2}{*}{ Daly (11) } & 30 & 61 & III (23) & 6 & 60 & 38 & 67 & 53 & 60 \\
\hline & & & IV (53) & & & & & & \\
\hline Sher (13) & 30 & $\mathrm{nr}$ & $\mathrm{nr}$ & 7 & $\mathrm{nr}$ & $\mathrm{nr}$ & $\mathrm{nr}$ & $91 \#$ & 85\# \\
\hline \multirow[t]{2}{*}{ Present analysis } & 53 & 60 & III (13) & 7 & 55 & 28 & 83 & 79 & 73 \\
\hline & & & IV (57) & & & & & & \\
\hline
\end{tabular}

Abbreviations: LRFS local recurrence-free survival, LRRFS locoregional recurrence-free survival, mts months, $n$ eligible patients, $n r$ not reported separately, OS overall survival, $R T$ radiotherapy, ${ }^{*}$ mean age; \#2 year actuarial estimates; three year actuarial estimates; ${ }^{* *}$ Crude rate. 
spreading retrograde along the inferior alveolar nerve, a type of recurrence already described in detail [8].

Concerning side effects, the acute toxicity grading was 2 in $27 \%$ of patients and 3 for $66 \%$. The late toxicity grading was 2 in $34 \%$ of patients and 3 in $11 \%$. The use of different methods for assessing toxicities and the variety of symptoms assessed makes it difficult to compare results across trials. However, our data do compare favorably with the toxicity rates outlined by Sher et al. assessed by CTCAE version 4.0. [13]. It is important to note that we did not observe acute toxicity related treatment interruptions. When late toxicity was assessed at the last follow-up visit, the rates were below the pre-RT morbidity symptoms. This could be partly due to increased pain medication, use of gastrostomy tubes and other medical interventions as well as full recovery from surgery. Our study is limited due to its retrospective nature. Despite this limitation it appears that LRRFS after postoperative IMRT is promising with acceptable acute and late toxicity rates.

\section{Conclusion}

Postoperative IMRT of locally advanced or high-risk OCC was associated with satisfying LRRFS. Acute and late toxicity rates were acceptable. Our patterns of failure analysis emphasizes the need to improve high-risk CTV target volume definition, as the majority of our locoregional recurrences occurred marginal to or outside of the high-risk CTV. Having seen unusual multifocal recurrences in 5 of 8 patients with both ECE and flap reconstruction, we propose to fully include the volume of flap reconstruction in the elective CTV in this scenario. Further improvement of high-risk CTV definition might generally transfer into better LRRFS.

\section{Competing interest}

The authors declare that there are no financial disclosures or conflict of interest that could be perceived as prejudicing the impartiality of the research reported.

\section{Authors' contributions}

Each author had participated sufficiently in the work to take public responsibility for appropriate portions of the content. AG, PG and DMA designed the study. SC performed the statistical analysis. AG, BB and PG collected the data and together with SC, AA, PM, WH and DMA interpreted the data. The manuscript was written by $A G$ and $P G$, all other authors helped and finally approved the final manuscript.

\section{Acknowledgements}

This work was presented at the 31st ESTRO Annual Scientific Meeting, Barcelona, Spain, May 9-13 2012.

\section{Author details}

${ }^{1}$ Department of Radiation Oncology and Division of Medical Radiation Physics, Bern University Hospital, Freiburgstrasse, 3010 Bern, Switzerland. ${ }^{2}$ SAKK Coordinating Center, Effingerstrasse 40, 3008 Bern, Switzerland. ${ }^{3}$ Department of Otorhinolaryngology, University Hospital Bern, Freiburgstrasse, 3010 Bern, Switzerland. ${ }^{4}$ Department of Craniomaxillofacial Surgery, University Hospital Bern, Freiburgstrasse, 3010 Bern, Switzerland.
Received: 25 July 2012 Accepted: 17 October 2012

Published: 22 October 2012

\section{References}

1. Kramer S, Gelber RD, Snow JB, Marcial VA, Lowry LD, Davis LW, Chandler R: Combined radiation therapy and surgery in the management of head and neck cancer: final report of study 73-03 of the Radiation Therapy Oncology Group. Head Neck Surg 1987, 10:19-30.

2. Lavaf A, Genden EM, Cesaretti JA, Packer S, Kao J: Adjuvant radiotherapy improves overall survival for patients with lymph node-positive head and neck squamous cell carcinoma. Cancer 2008, 112:535-543.

3. Bernier J, Cooper JS, Pajak TF, van Glabbeke M, Bourhis J, Forastiere A, Ozsahin EM, Jacobs JR, Jassem J, Ang KK, Lefèbvre JL: Defining risk levels in locally advanced head and neck cancers: A comparative analysis of concurrent postoperative radiation plus chemotherapy trials of the EORTC (\#22931) and RTOG (\#9501). Head Neck 2005, 27:843-850.

4. Nutting CM, Morden JP, Harrington KJ, Urbano TG, Bhide SA, Clark C, Miles EA, Miah AB, Newbold K, Tanay M, Adab F, Jefferies SJ, Scrase C, Yap BK, A'Hern RP, Sydenham MA, Emson M, Hall E: PARSPORT trial management group: Parotid-sparing intensity modulated versus conventional radiotherapy in head and neck cancer (PARSPORT): a phase 3 multicenter randomized controlled trial. Lancet Oncol 2011, 12:127-136.

5. Buettner F, Miah AB, Gulliford SL, Hall E, Harrington KJ, Webb S, Partridge M, Nutting CM: Novel approaches to improve the therapeutic index of head and neck radiotherapy: An analysis of data from the PARSPORT randomised phase III trial. Radiother Oncol 2012, 103:82-87.

6. van der Laan HP, Christianen ME, Bijl HP, Schilstra C, Langendijk JA: The potential benefit of swallowing sparing intensity modulated radiotherapy to reduce swallowing dysfunction: An in silico planning comparative study. Radiother Oncol 2012, 103:76-81.

7. Studer G, Zwahlen RA, Graetz KW, Davis BJ, Glanzmann C: IMRT in oral cavity cancer. Radiat Oncol 2007, 2:16.

8. Yao M, Chang K, Funk GF, Lu H, Tan H, Wacha J, Dornfeld KJ, Buatti JM: The failure patterns of oral cavity squamous cell carcinoma after intensity-modulated radiotherapy: The University of lowa experience. Int J Radiat Oncol Biol Phys 2007, 67:1332-1341.

9. Gomez DR, Zhung JE, Gomez J, Chan K, Wu AJ, Wolden SL, Pfister DG, Shaha A, Shah JP, Kraus DH, Wong RJ, Lee NY: Intensity-modulated radiotherapy in postoperative treatment of oral cavity cancers. Int J Radiat Oncol Biol Phys 2009, 73:1096-1103.

10. Chen WC, Hwang TZ, Wang WH, Lu CH, Chen CC, Chen CM, Weng HH, Lai $\mathrm{CH}$, Chen MF: Comparison between conventional and intensitymodulated post-operative radiotherapy for stage III and IV oral cavity cancer in terms of treatment results and toxicity. Oral Oncol 2009, 45:505-510.

11. Daly ME, Lee QT, Kozak MM, Maxim PG, Murphy JD, Hsu A, Loo BW Jr, Kaplan MJ, Fischbein NJ, Chang DT: Intensity-modulated radiotherapy for oral cavity squamous cell carcinoma: patterns of failure and predictors of local control. Int J Radiat Oncol Biol Phys 2011, 80:1412-1422.

12. Turaka A, Li T, Sharma NK, Li L, Nicolaou N, Mehra R, Burtness B, Cohen RB, Lango MN, Horwitz EM, Ridge JA, Feigenberg SJ: Increased recurrences using intensity-modulated radiation therapy in the postoperative setting. Am J Clin Oncol 2010, 33:599-603.

13. Sher DJ, Thotakura V, Balboni TA, Norris CM Jr, Haddad RI, Posner MR, Lorch J, Goguen LA, Annino DJ, Tishler RB: Treatment of oral cavity squamous cell carcinoma with adjuvant or definitive intensity-modulated radiation therapy. Int J Radiat Oncol Biol Phys 2011, 81:e215-e222.

14. Greene FL, Page DL, Fleming ID, et al (Eds): AJCC cancer staging manual. 6th edition. Philadelphia: Springer; 2002.

15. Grégoire V, Eisbruch A, Hamoir M, Levendag P: Proposal for the delineation of the nodal CTV in the node-positive and the post-operative neck. Radiother Oncol 2006, 79:15-20.

16. Eisbruch A, Foote RL, O'Sullivan B, Beitler JJ, Vikram B: Intensity-modulated radiation therapy for head and neck cancer: emphasis on the selection and delineation of the targets. Semin Rad Oncol 2002, 12:238-249.

17. Dawson LA, Anzai Y, Marsh L, Martel MK, Paulino A, Ship JA, Eisbruch A: Patterns of local-regional recurrence following parotid-sparing conformal and segmental intensity-modulated radiotherapy for head and neck cancer. Int J Radiat Oncol Biol Phys 2000, 46:1117-1126. 
18. Chao KS, Ozyigit G, Tran BN, Cengiz M, Dempsey JF, Low DA: Patterns of failure in patients receiving definitive and postoperative IMRT for head-and-neck cancer. Int J Radiat Oncol Biol Phys 2003, 55:312-321.

19. Tan HK, Giger R, Auperin A, Bourhis J, Janot F, Temam S: Salvage surgery after concomitant chemoradiation in head and neck squamous cell carcinomas - stratification for postsalvage survival. Head Neck 2010, 32:139-147.

doi:10.1186/1748-717X-7-175

Cite this article as: Geretschläger et al:: Outcome and patterns of failure after postoperative intensity modulated radiotherapy for locally

advanced or high-risk oral cavity squamous cell carcinoma. Radiation

Oncology 2012 7:175.

\section{Submit your next manuscript to BioMed Central and take full advantage of:}

- Convenient online submission

- Thorough peer review

- No space constraints or color figure charges

- Immediate publication on acceptance

- Inclusion in PubMed, CAS, Scopus and Google Scholar

- Research which is freely available for redistribution 